\title{
Laboratory animal allergy: anaphylaxis from a needle injury
}

\author{
A David Watt, Charles P McSharry
}

\begin{abstract}
A 32 year old male research physician accidentally received a minor wound from a needle which had been previously used on rabbit tissue. Within 15 minutes serious anaphylactic reactions started and he was taken to hospital where his condition stabilised within five hours. Serum immunoglobulin $E$ antibodies to rabbit epithelium were high $(16 \cdot 2 \mathrm{U} / \mathrm{ml})$, although other antibody titres were low. Allergy tests were not carried out before employment, so this alarming scenario could not have been predicted. People with confirmed laboratory animal allergy should be warned of the dangers of continued unprotected exposure and avoidance of the allergen should be encouraged by good laboratory practice and respiratory protective equipment.
\end{abstract}

(Occup Environ Med 1996;53:573-574)

Keywords: anaphylaxis; needle injury; allergy to rabbits

Laboratory animal allergy (LAA) is a familiar and accepted occupational hazard which rarely presents for medical attention and is generally not regarded as a major health risk. ${ }^{1}$ Among exposed workers $40 \%$ report symptoms consistent with LAA and $35 \%$ have serological evidence of sensitivity (immunoglobulin E (IgE) antibody to antigens derived from animals). Rabbits seem to be a major source of symptoms. ${ }^{2}$ Symptoms are predominantly mild, caused by inflammation of the nose or eyes in response to airborne allergens. ${ }^{2}$ We report a case of a serious anaphylactic response in a person allergic to rabbits following a superficial needle injury after a procedure in which the needle had been used on rabbit tissue.

\section{Case report}

THE PATIENT

A 32 year old male physician had been working on a research project which involved rabbits for two and a half years. He had not been assessed by an occupational health service before starting the project. He was aware of an allergy to rabbits because of rhinitis and conjunctivitis related to exposure but he did not think that this was sufficiently serious to report it to either his general practitioner or the occupational health service. He noticed that symptoms were particularly obvious on the first re-exposure to rabbits after a period away, and considered that the symptoms were getting progressively worse with time. He had no history of asthma, eczema, hay fever, or cigarette smoking but he thought he was allergic to cats. $\mathrm{He}$ had not had any anaphylactic reactions in the past. He had a history of exposure to a pet rabbit at the age of four for about a year but the rabbit was removed when his brother developed asthma thought to be caused by rabbit sensitivity.

\section{THE REACTION}

The patient sustained a needle injury after a procedure which involved cannulating an ear artery of a rabbit. He turned, close to a colleague who was holding the cannula needle and his bare forearm sustained an oblique puncture wound. The wound bled slightly and within 15 minutes he was aware of itching of the skin of his arm around the wound, nasal irritation, swelling of his face, and a sensation that his ears were blocked. A weal and flare reaction was present around the scratch and he rapidly developed urticaria over his whole body. His throat became tight and he was unable to speak. His colleagues noticed that he was in distress and he was taken to the medical ward where he was treated with intravenous hydrocortisone and oral antihistamines. His condition settled within five hours and he was discharged from inpatient care.

\section{SEROLOGY}

Serum IgE antibody titres were measured by commercial enzyme immunoassay (Pharmacia UK, Milton Keynes). There were no significant titres against house dust mite (Dermatophagoides pteronyssinus), grass pollen (meadow fescue), latex, and the epithelia of dog, rat, mouse, hamster, and guinea pig. The patient had a moderate titre of IgE antibody to cat dander (2.04 arbitrary units $/ \mathrm{ml})$ and a high titre to rabbit epithelium $(16 \cdot 2 \mathrm{U} / \mathrm{ml})$. The total IgE titre was $162 \mathrm{kU} / \mathrm{l}$.

The specificity of the IgE antibody measurement was tested by RAST inhibition with 
rabbit serum and epithelium preparations (Sera lab and Bencard respectively). There was no detectable IgG antibody activity, measured by enzyme immunoassay, against these antigens.

After six months, during which time there was no contact with rabbits (he changed job), a repeat blood sample showed that there was a reduction in total $\mathrm{IgE}$ to $130 \mathrm{kU} / \mathrm{l}$ and a reduction of rabbit specific IgE to $11.0 \mathrm{U} / \mathrm{ml}$.

\section{Comment}

We contend that this anaphylactic reaction was due to a response mediated by IgE by trace amounts of rabbit serum proteins accidentally introduced into the superficial layers of the skin by a cannula needle. The temporal relation of injury and symptoms is sufficient in our view, coupled with a raised IgE antibody titre to rabbit protein, to make an assumption of a causal link. Allergenic proteins in rabbit serum have been described, mainly immunoglobulin light chain, ${ }^{4}$ and the identity of the main allergens in the rabbit serum and dander in this case were shown by inhibition of the patient's IgE antibody activity. Several characteristics of this patient were atypical of people predisposed to develop LAA. He was non-atopic (no IgE antibody to the common inhaled allergens, grass pollen, and house dust mite) and was a non-smoker, both risk factors associated with.LAA. ${ }^{5} \mathrm{He}$ had IgE antibody against rabbit allergens and no other laboratory animal, whereas it is more common to have a range of these antibodies. ${ }^{2} \mathrm{His}$ anaphylactic response was also uncommon; we can find no previous report of a similar reaction despite needle injuries being a known hazard for laboratory animal handlers and veterinary surgeons. ${ }^{2}$ A localised weal and flare reaction to a cat scratch in people allergic to cats is common but there seem to be no reports of anaphylaxis in these people. Anaphylaxis, occasionally fatal, has been reported in response to small amounts of allergen from mosquito bites and bee stings, ${ }^{2}$ intradermal skin testing, ${ }^{2}$ and immunotherapy, ${ }^{6}$ but there is a negligible risk with prick tests to common allergens.

What could explain his particular acute sensitivity? His previous exposure to a pet rabbit as a child may be relevant. Rabbit allergen is airborne and the response is mild eye and nose irritation; however, asthma has been described $^{3}$ and indeed the pet rabbit had to be removed because of the patient's brother's asthma. It may be that this early exposure potentiated the patient to produce excess IgE to rabbit allergens in later life. He was aware of an increasing tendency to allergic symptoms when exposed to rabbits, especially after a period away from contact.

Like most anaphylactic reactions, this event was serious and alarming. Warnings that "Symptoms can be provoked by allergen intro- duced into a break in the skin caused by scratches, bites or instruments" 5 and "... anaphylactic shock may also occur" 7 form part of the scientific literature available to those who work with laboratory animals. ${ }^{1}$ We suggest that animal house codes of practice should contain guidelines and provision be made for dealing with anaphylaxis either on site or at the nearest casualty department. Personnel should be trained to recognise the signs and symptoms of anaphylaxis as part of their training on LAA. They should treat such signs seriously and know what to do. There should be guidelines on working alone even though this is not legally prohibited. "Sharps" should be disposed of immediately. Health assessment before employment ${ }^{1}$ is an essential part of an employer's duty when exposing employees to the hazard of animal dander allergy. It fulfils the purpose of identifying people with existing animal allergies, creates baseline recordings of lung function, and provides warnings and education about hazards, their avoidance, and personal protection. People with symptoms suggestive of allergy should have frequent assessments during their initial exposures as most workers who develop allergy or asthma usually do so in their first year at work ${ }^{79}$ and IgE titres for suspect allergens should be measured. Measurements of antibodies to IgE, whether positive or negative, are a useful adjunct and essential for follow up studies. An increasing $\operatorname{IgE}$ antibody titre to animal allergens or the development of symptoms indicate that avoidance is essential. Delays can result in increasingly compromised long term lung function. ${ }^{10}$ People with confirmed LAA should be warned of the dangers of continued unprotected exposure and avoidance of the allergen should be encouraged by good laboratory practice and respiratory protective equipment.

We acknowledge Mr C Cruickshank for his help with IgE serology typing and Mrs $M$ Wallace for typing the manuscript.

1 What you should know about allergy to laboratory animals Health and Safety Commission, HMSO 1990, ISBN 0 118855271 .

2 Venables KM, Tee RD, Hawkins ER, Gordon BJ, Wale CJ, Farrer NM, et al. Laboratory animal allergy in a pharmaceutical company. Br F Ind Med 1988;45:660-6.

3 Nishimura M, Suzuki A, Nakano I. A case of bronchial asthma showing dual asthmatic response to rabbit hair. asthma $¥$ Thoracic Dis $1985 ; 23: 1036-40$.

4 Price JA, Longbottom JL. Allergy to rabbits 1. Specificity and non-specificity of RAST and cross-radioimmunoelectrophoresis due to the presence of light chains in rabbit allergenic extracts. Allergy 1986;41:603-12.

5 Venables KM, Upton JL, Hawkins ER, Tee RD Longbottom JC, Newman-Taylor AJ. Smoking, atopy, and laboratory animal allergy. $B r \mathcal{F}$ Ind Med 1988;45 667-71.

6 Committee on the Safety of Medicines. CSM update: disensitising vaccines. $B M F$ 1986;293:248-50.

7 Davies GE, Thompson AV, Niewola Z, Burrows GE, Teesdale EC, Bird DJ, et al. Allergy to laboratory animals. A retrospective and a prospective study. $\mathrm{Br} \mathcal{F}$ Ind Med 1983;40:442-9.

8 Health and safety in animal facilities. London: Health and Safety Commission, HMSO, 1992. (ISBN 011886353 3). Safety Commission, HMSO, 1992 . (ISBN 0118863533 ). tional asthma. Br ₹ Ind Med 1987;44:73-5.

10 Gannon PF, Weir DC, Robertson AS, Barge PS. Health, employment and financial outcome in workers with occupational asthma. F Allergy Clin Immunol 1993;91:1121-7. 